\title{
Acquired Color Vision Defects in Chronic Heavy Smoking
}

Keywords: Cigarette smoking; Visual system; Color discrimination; Color vision; Lanthony D15d

\section{Abstract}

Nicotine, a psychoactive compound of cigarette, is an alkaloid that binds and activates nicotinic acetylcholine receptors on the retina and lateral geniculate nucleus, being able to affect visual spatial processing. Losses in color vision have been associated with chronic exposure to cigarette. Since not all tests of color discrimination investigation are designed to detect acquired losses, the Lanthony D 15 desaturated (D15d) panel presents itself as an essential and reliable tool for this identification. The D15 is a simple 15 cap color arrangement test, designed to identify mild acquired color losses and can be quickly administered under standard conditions. This test generally describes loss of color discrimination, affecting both the blue-yellow axis and the red-green axis. We tested 20 non-smokers (10 males) and 20 smokers (10 males). All subjects were free of any neurological disorder, identifiable ocular disease and had normal acuity. No abnormalities were detected in the fundoscopic examination. Color discrimination was evaluated with the Lanthony D15d test. Results from both groups were compared using the Mann-Whitney U Test. The number of error in the D15d was higher for smokers when compared to non-smokers. These results suggest that not only chronic exposure to cigarette compounds but also smoking habit affected spatial vision. This highlights the importance of understanding diffuse effects of smoking compounds on color processing.

\section{Introduction}

Cigarette smoke is probably the most significant source of exposure to toxic chemicals for humans, involving health-damaging components such as carbon monoxide, toluene, hydrogen cyanide, formaldehyde and nicotine [1]. Data from the World Health Organization (WHO) hypothesize that by 2030, cigarettes could kill nearly 9 million people a year around the world $[2,3]$.

Some of the cigarette compounds are linked to the increased incidence of cardiovascular disease, including coronary heart disease, cerebrovascular disease (stroke, transient ischemic attacks) and vascular diseases (aortic aneurysm and atherosclerosis), being the primary cause of the obstructive pulmonary disease [4]. Nicotine, one of psychoactive compounds of cigarette, is an alkaloid that binds and activates nicotinic acetylcholine receptors (nAChRs) [5]. It is known that there are nAChRs receptors in functional units of visual processing such as retinal cells, lateral geniculate nucleus, and primary visual cortex of numerous species $[6,7]$.

The exact mechanisms of color processing impairment are still not well specified; however, it is suggested that the imbalance in the neurotransmission of acetylcholine, dopamine and glutamate as well as impairments in the receptors functioning or conformation alter visual processing [8-10]. Studies have shown that nicotinic agonists affects the release of these neurotransmitters $[5,11]$.
Journal of

\section{Addiction \& Prevention}

\begin{abstract}
Thiago Monteiro de Paiva Fernandes ${ }^{1,2 *}$, Natalia Leandro de Almeida ${ }^{2}$ and Natanael Antonio dos Santos ${ }^{1,2}$
\end{abstract}

${ }^{1}$ Department of Psychology, Federal University of Paraiba, Joao Pessoa, Brazil

${ }^{2}$ Perception, Neuroscience and Behavior Laboratory, Federal University of Paraiba, Brazil

*Address for Correspondence

Thiago Monteiro de Paiva Fernandes, Department of Psychology, Federal University of Paraiba, Joao Pessoa, Brazil, Tel: +55-83-216-7064; E-mail: paivatm@gmail.com

Submission: 17 March, 2017

Accepted: 20 April, 2017

Published: 27 April, 2017

Copyright: (๑) 2017 Fernandes TM, et al. This is an open access article distributed under the Creative Commons Attribution License, which permits unrestricted use, distribution, and reproduction in any medium, provided the original work is properly cited.

Chronic heavy smoking in dependent users has been associated with losses in processing of the red-green color vision system, suggesting that this system is more sensitive to the effects of cigarette compounds $[12,13]$.

The relationship between chronic smoking visual impairments still has its gaps. Based on the existing literature, the existing data are dissonant and reflect the need to use a reliable tool to evaluate the acquired losses [12-17]. Also, suggest that an effort to increase the accuracy of testing procedures is needed. Due to diverse lighting conditions or differences in analysis procedures, the existing results point to the existence of small changes in color vision, but not enough to characterize acquired losses.

The use of a quick and effective test to evaluate the color vision is essential. Therefore, panel tests, such as Lanthony D15d, are presented as the best choices for rapid screening and observation of acquired or congenital impairments $[16,18]$.

Based on the evidence that cigarette compounds are harmful and affect visual processing, we expect to find significant changes in the processing of the red-green color vision system in smokers $[12,13,15]$. However, since the acquired losses may evolve to a redgreen defect after starting a blue-yellow defect, the losses observed in our study may be global, involving both systems [19]. Our premise is that chronic smoking habit will affect color discrimination, especially considering the existence of harmful cigarette compounds.

The purpose of the present study was to assess the influence of chronic heavy smoking on color discrimination through a sensitive quantitative method of assessment, the Lanthony D15d.

\section{Material and Methods}

\section{Participants}

This research followed the ethical principles from the Declaration of Helsinki and was approved by the Committee of Ethics in Research 
of the Health Sciences Center of Federal University da Paraiba (CAAE: 60944816.3.0000.5188). Written informed consent was obtained from all participants.

In this study, 20 healthy non-smokers (Mean age $=33.5$ years; $\mathrm{SD}=7.88 ; 10$ males) and 20 heavy cigarette smokers (Mean age = $31.3 ; \mathrm{SD}=5.90 ; 10$ males), from 25 to 45 years, who were working as staff or were students at Federal University of Paraiba, were recruited through newspaper advertisements.

Participants were excluded if indicated any one of the following criteria:

(I) Older than 45 years;

(II) Cardiac, Hepatic, Renal or Neurological disorders;

(III) Migraine,

(IV) A history of head trauma;

(V) Color blindness;

(VI) Current or previous drug abuse or drinking more than 10 alcoholic drinks per week and;

(VII) Current use of medications that may affect visual processing and cognition.

Female participants that used contraception were only tested outside their menstrual period to minimize confounds of hormonal differences.

In addition, subjects were required to have a good ocular health: no abnormalities were detected in the fundoscopic examination and in the optical coherence tomography exam. All observers were screened for color blindness using Ishihara's tests for color deficiency and had normal or corrected-to-normal vision as determined by a visual acuity of at least 20/20 [20].

Smokers reported a smoking history of at least 8 years, currently smoked more than 20 cigarettes/day and had a score $>5$ on the Fagerström Test for Nicotine Dependence (FTND) [21]. Smokers began smoking on average at the age of 16.5 years $(\mathrm{SD}=3.25)$ and had been smoking on average 15 years $(S D=6.45)$. All subjects were asked to abstain from caffeine containing products starting at 12.00 $\mathrm{pm}$ on the evening prior to the measurements. Smokers were allowed to smoke until the beginning of experiment. Non-smokers had never smoked a cigarette. There were no statistical differences between depression and anxiety symptoms pre- and post-experiment, as measured by Hamilton Scale for Depression and Hamilton Anxiety Rating Scale.

The groups did not differ in age, $\mathrm{F}(2,37)=0.14, \mathrm{p}=0.94$, or ratio of males to females (Pearson's Chi Square Value $=1.7, \mathrm{~ns}$ ). There was also no difference in FTND scores $(\mathrm{t}(1)=2.23, \mathrm{p}=0.76)$, age at first cigarette use $(t(1)=3.59, p=0.73)$, and years of cigarette use $(t(1)=$ $1.63, \mathrm{p}=0.93)$ between the two groups of smokers who took part in this experiment (Table 1).

\section{Color Vision Test}

Color vision was assessed with the Lanthony D15d test (D15d). D15d is an arrangement test composed of a fixed reference disc and
Table 1: Demographics and cigarettes use in chronic smokers and nonsmokers.

\begin{tabular}{|c|c|c|c|c|}
\hline \multicolumn{2}{|c|}{ Variables } & $\begin{array}{c}\text { Non-Smokers } \\
(n=20)\end{array}$ & $\begin{array}{c}\text { Smokers } \\
(n=20)\end{array}$ & $\begin{array}{c}\text { T-test } \\
\text { ( } p \text {-value })\end{array}$ \\
\hline \multirow{2}{*}{ Gender } & Male & 10 & 10 & - \\
\hline & Female & 10 & 10 & - \\
\hline \multirow[b]{2}{*}{ Age } & Young Adults & 10 & 10 & - \\
\hline & $\begin{array}{l}\text { Middle-aged } \\
\text { Adults }\end{array}$ & 10 & 10 & - \\
\hline \multirow{2}{*}{$\begin{array}{l}\text { Education } \\
\text { Level }\end{array}$} & High School & 3 & 5 & - \\
\hline & College & 17 & 15 & - \\
\hline \multirow{3}{*}{ Cigarette use } & Age at first use & - & $17 \pm 1.4$ & $5.71(0.99)$ \\
\hline & Years of use & - & $15 \pm 6,9$ & $1.63(0.93)$ \\
\hline & FTND & - & $7 \pm 1,7$ & $2.35(0.98)$ \\
\hline
\end{tabular}

15 other discs with different shades of the same brightness (8) and saturation (2) covered by Munsell papers [16,17]. The bottom of these discs contains the numbering from 1 to 15 which represents the correct sequence. The instrument is arranged on a table with a black background, receiving illumination from a $60 \mathrm{~W}$ incandescent lamp with an angle of $45^{\circ}$. The distance from the point of illumination to the box to order the pieces measures $21 \mathrm{~cm}$, as required by the manual for lamps with the mentioned [22].

The application of the test followed the instructions in the manual. All the sources of illumination, except the required, were excluded. Thus, the discs were randomized and the role of participants was simply to arrange the discs in the correct color order as they perceive it and the arrangement is then evaluated. Participants with color perception deficiencies will have difficulties trying to arrange the colored discs and will usually make mistakes [16].

The evaluation of the patient's arrangement differentiates normal color perception from congenital or acquired moderate and strong defects in deutan (green and green weak blindness), protan (red blindness) or tritan (blue-yellow blindness) color discrimination. The evaluation of the results can be done qualitatively or quantitatively. However, the D15d test should not be analyzed only qualitatively when it is desired to discover early losses in color vision [22]. Thus, the CCI (Color Confusion Index) of Bowman was used to quantitatively evaluate the performance of each participant [23].

The desaturated test is much more difficult to complete correctly than the Farnsworth D - 15. It is a much more sensitive test.

\section{Data Analysis}

Statistical analysis was performed with the statistical package for the social sciences (SPSS) version 23.0. The distributions for each group were compared with Kolmogorov Smirnov. Both groups showed non-normal distribution, thus non-parametric statistical methods were used to analyze the data. For all intergroup comparisons, Mann-Whitney U test was used. Spearman's rank correlation coefficients (rho) was conducted to assess the relationship between bio-socio-demographic variables such as age, gender, level of schooling, FTND and visual performance for Lanthony D15d.

Results are presented as medians. Center lines show the medians; box limits indicate the $25^{\text {th }}$ and $75^{\text {th }}$ percentiles as determined by SPSS software; whiskers extend 1.5 times the interquartile range from the 
$25^{\text {th }}$ and $75^{\text {th }}$ percentiles (ends of the whiskers are the maximum and minimum values). Bonferroni correction was the method of adjusting p-value that we used and the data was accepted as statistically significant when $\mathrm{p}<0.025$.

\section{Results}

\section{Demographics}

Table 1 presents the demographic data of participants included in the analysis. The mean age of smokers was 31 years $(\mathrm{SD}=5.89)$. Education level mean was 15 years $(\mathrm{SD}=1.86)$. Age at first cigarette smoking was 17 years $(\mathrm{SD}=1.4)$ and have been smoking for 15 years $(S D=6.9)$. All smokers' participants scored an average of seven on FTND. The participants in the non-smokers group were matched for age, education level and sex.

\section{Lanthony D15d}

Table 2 shows the values of the descriptive statistics.

Table 2: Descriptive statistics of mean, standard deviation (SD), median and interquartile range (IQR) for the $\mathrm{CCl}$.

\begin{tabular}{|l|c|c|c|c|}
\hline & Mean & SD & Median & IQR \\
\hline Non-smokers & 1.249 & 0.111 & 1.210 & 0.210 \\
\hline Smokers & 1.860 & 0.352 & 2.040 & 1.180 \\
\hline
\end{tabular}

Results for the D15d test are shown in Figure 1. Group color confusion indexes for smokers were higher than for non-smokers ( $U$ $=22 ; \mathrm{r}=-0.52, \mathrm{p}=006)$. The Jonckheere test revealed a significant trend in the data $(\mathrm{J}=251, \mathrm{z}=2.47, \mathrm{r}=0.43)$; thus, smokers presented almost 1.5 (0.09 log units) times more discrimination errors than the non-smokers group (Figure 1).

Spearman's rank coefficient did not show significant correlation between CCI and education level $(\mathrm{rs}=0.284, \mathrm{p}=0.225)$ and gender ( $\mathrm{rs}=0.010, \mathrm{p}=0.966$ ). There was a statistically significant correlation between age ( $r s=0.610, p=0.004)$ and CCI data, where middle-aged adults had poorer discrimination than younger adults did. There was no correlation between FTND and CCI ( $p>0.05)$.

\section{Discussion}

The data indicated that smokers demonstrated acquired color deficits when compared to non-smokers. For example, non-smokers CCI were about 1.5 times higher than smokers did (Figure 1). May be it is early to conclude that there are impairments in the red-green and blue-yellow color vision system, but the D15d was sensitive enough to detect these losses.

Numerous compounds in the cigarette smoke such as carbon monoxide, toluene, tar, nickel and many others are, by themselves, potentially harmful to health [24-26]. Chronic exposure to these substances can cause poisoning and consequent retinopathy $[27,28]$. Thus, the intent of the present study was not to specifically evaluate the effect of nicotine, one of the components of the cigarette, but to observe and investigate the effects of chronic cigarette smoking in color vision processing.

Although smoking habit between woman and men are slightly different, there were no gender differences in our data [29]. However, we observed differences between age and CCI, with middle-aged adults had poorer CCI than young adults. This same pattern was found in other studies using psychophysics [30,31]. It is hypothesized that the normal aging affects visual processing in humans, being consistent with Faubert's theory of visual perception and aging [32].

Hazardous compounds of tobacco cigarettes can play a significant role in retinal sensitivity loss in heavy smokers likewise as addiction chemical modulators through dopamine (DA), GABA and glutamate neurotransmission deficits [33-36]. Nicotine, one of tobacco psychoactive components, enhances DA release through a dynamic balance of activation and desensitization of nAChRs located mainly in the ventral tegmental area and in the striatum $[11,36]$. As stated, since there are also nAChRs and DA receptors on the retina, it is not hard to understand that chronic smoking would impair sensory integration at some points, especially considering early visual processing [37,38].

Cigarette smoke is a chemical mixture that involves components such as organic solvents (toluene or formaldehyde). As observed in other studies, chronic exposure to solvents affected visual processing [22]. Thus, chronic cigarette smoking, including toxic smoke inhalation, points to another possible mechanism of visual impairment, toxic optic neuropathy [26].

Finally, our results indicated that smokers presented less discrimination when compared to the non-smokers group. There were no observed evidence of the existence of selective changes in color vision system, but the data support the idea that tobacco compounds affected color vision as a whole. Even though there are a limited number of studies about smoking and visual processing, specifically about color vision, our limitations need to be considered. First, the major limitation is that this was an observational study, and such a design does not permit evaluation of the physiological or genetic associations between smoking and color vision per se. However, we cannot fail to draw parallels with physiology, as pointed out by classical studies of visual psychophysics $[10,31,39]$. Another limitation is in relation to the sample age. In a similar study, there was a large difference between older and younger smokers [15]. Although it is not possible to dissociate normal aging from the natural decay caused to vision, our intention is to add a sample with

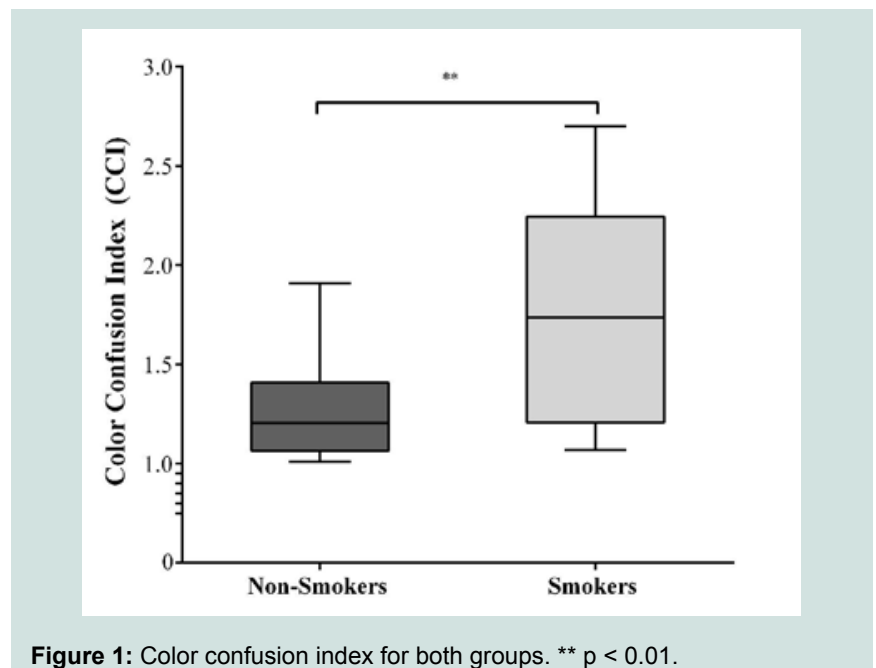

Figure 1: Color confusion index for both groups. ${ }^{* *} p<0.01$ 
older participants and make the same comparison used here.

Finally, our intention was not to evaluate separately cigarette compounds, but to point to a new direction of smoking studies. Clearly, further work is needed but this study highlights the relationship between smoking and color discrimination.

\section{References}

1. Mathers CD, Loncar D (2006) Projections of global mortality and burden of disease from 2002 to 2030. PLoS Med 3: e442.

2. World Health Organization (2013) WHO report on the global tobacco epidemic, 2013: Enforcing bans on tobacco advertising, promotion and sponsorship. Geneva, Switzerland.

3. World Health Organization (2013) WHO report on the global tobacco epidemic, 2015: Raising taxes on tobacco. Geneva, Switzerland.

4. Ockene IS, Miller NH (1997) Cigarette smoking, cardiovascular disease, and stroke: a statement for healthcare professionals from the American Hear Association. American Heart Association Task Force on Risk Reduction. Circulation 96: 3243-3247.

5. Balfour DJ, Munafò MR (2015) The neuropharmacology of nicotine dependence: current topics in behavioral neurosciences. Springer, Switzerland.

6. Metherate R (2004) Nicotinic acetylcholine receptors in sensory cortex. Learn Mem 11: 50-59.

7. Paterson D, Nordberg A (2000) Neuronal nicotinic receptors in the human brain. Prog Neurobiol 61: 75-111.

8. Brandies R, Yehuda S (2008) The possible role of retinal dopaminergic system in visual performance. Neurosci Biobehav Rev 32: 611-656.

9. DeValois RL, DeValois KK (1990) Spatial Vision, Oxford University Press, USA.

10. DeValois KK, Webster MA (2011) Color vision. Scholarpedia 6: 3073.

11. D'Souza MS, Markou A (2011) Neuronal mechanisms underlying development of nicotine dependence: implications for novel smoking-cessation treatments. Addict Sci Clin Pract 6: 4-16.

12. Fernandes TM, Almeida NL, dos Santos NA (2017) Comparison of color discrimination in chronic heavy smokers and healthy subjects. F1000 Res 6: 85 .

13. Naser NT, Loop M, Than T, Varghese S, Hartmann EE (2011) Color vision: effects of nicotine gum in non-smokers. Invest Ophthalmol Vis Sci 52: 4902.

14. Varghese SB, Reid JC, Hartmann EE, Keyser KT (2011) The effects of nicotine on the human electroretinogram. Invest Ophthalmol Vis Sci 52: 94459451.

15. Kunchulia M, Pilz KS, Herzog MH (2014) Small effects of smoking on visual spatiotemporal processing. Sci Rep 4: 7316 .

16. Lanthony $P$ (1978) The desaturated panel D-15. Doc Ophthalmol 46: 185189.

17. Lanthony P, Dubois-Poulsen A (1973) Desaturated farnsworth 15. Bull Soc Ophtalmol Fr 73: 861-866.

18. Geller AM (2001) A table of color distance scores for quantitative scoring of the Lanthony desaturate color vision test. Neurotoxicol Teratol 23: 265-267.

19. Nork TM (2000) Acquired color vision loss and a possible mechanism of ganglion cell death in glaucoma. Trans Am Ophthalmol Soc 98: 331-363.

20. Ishihara S (1972) Tests for colour-blindness (38 plates edition): the series of plates designed as a test for colour-blindness. Kanehara Shuppan, Tokyo, Japan.

21. Heatherton TF, Kozlowski LT, Frecker RC, Fagerström KO (1991) The Fagerström test for nicotine dependence: a revision of the Fagerström Tolerance Questionnaire. Br J Addict 86: 1119-1127.

22. Oliveira AR (2015) Chromatic and achromatic psychophysical assessments of men and women exposed to organic solvents. Federal University of Paraiba, João Pessoa, Brazil.

23. Bowman KJ (1982) A method for quantitative scoring of the Farnsworth Pane D-15. Acta Ophthalmol (Copenh) 60: 907-916.

24. Talhout R, Schulz T, Florek E, van Benthem J, Wester $P$, et al. (2011) Hazardous compounds in tobacco smoke. Int $\mathrm{J}$ Environ Res Public Health 8: $613-628$

25. Swan GE, Lessov-Schlaggar CN (2007) The effects of tobacco smoke and nicotine on cognition and the brain. Neuropsychol Rev 17: 259-273.

26. Sharma P, Sharma R (2011) Toxic optic neuropathy. Indian J Ophthalmo 59: $137-141$

27. Kelley JS, Sophocleus GJ (1978) Retinal hemorrhages in subacute carbon monoxide poisoning. Exposures in homes with blocked furnace flues. JAMA 239: 1515-1517.

28. Sevel D, Freedman A (1967) Cerebro-retinal degeneration due to carbon dioxide poisoning. Br J Ophthalmol 51: 475-482.

29. Muir AD, McKeown PP, Bayraktutan U (2010) Role of gender, smoking profile, hypertension, and diabetes on saphenous vein and internal mammary artery endothelial relaxation in patients with coronary artery bypass grafting. Oxid Med Cell Longev 3: 199-205.

30. Derefeldt G, Lennerstrand G, Lundh B (1979) Age variations in normal human contrast sensitivity. Acta Ophthalmol (Copenh) 57: 679-690.

31. Sieiro RD, Coelho LM, Boas PC, Fonseca SC, Souza SR, et al. (2016) Contrast sensitivity assessment in different age group in medium and high spatial frequency. J Ophthalmol 75: 296-299.

32. Faubert J (2002) Visual perception and aging. Can J Exp Psychol 56: 164 176.

33. Uz E, Sahin S, Hepsen IF, Var A, Sogut S, et al. (2003) The relationship between serum trace element changes and visual function in heavy smokers. Acta Ophthalmol Scand 81: 161-164.

34. Radcliffe KA, Fisher JL, Gray R, Dani JA (1999) Nicotinic modulation of glutamate and GABA synaptic transmission of hippocampal neurons. Ann N Y Acad Sci 868: 591-610.

35. Timmerman W, Westerink BH (1997) Brain microdialysis of GABA and glutamate: what does it signify? Synapse 27: 242-261.

36. Levin ED (2001) Nicotinic receptors in the nervous system. CRC Press Washington DC, USA.

37. Besson M, Granon S, Mameli-Engvall M, Cloëz-Tayarani I, Maubourguet N et al. (2007) Long-term effects of chronic nicotine exposure on brain nicotinic receptors. Proc Natl Acad Sci U S A 104: 8155-8160.

38. Vallejo YF, Buisson B, Bertrand D, Green WN (2005) Chronic nicotine exposure upregulates nicotinic receptors by a novel mechanism $\mathrm{J}$ Neurosci 25: 5563-5572.

39. Cornsweet T (2012) Visual perception. Academic Press, USA, pp. 492.

\section{Acknowledgements}

National Brazilian National Council of Technological and Scientific Development (CNPq), Brazil (303822/2010-4), sponsored this paper. 